\title{
Sarı Kantaron (Hypericum perforatum L.) Fenoliklerinin Karakterizasyonu, Antioksidan ve Antimikrobiyal Potansiyelinin Belirlenmesi
}

Araștırma Makalesi

Öz

\author{
Birgül BURUNKAYA ${ }^{1}$, Serkan SELLİ ${ }^{2}$, Hasim KELEBEK ${ }^{1 *}$
}

$\mathrm{Bu}$ çalışmada sarı kantaron (Hypericum perforatum L.) bitkisinin farklı çözgenler (etanol, metanol, ayçiçek yağı, zeytinyağı ve su) kullanılarak elde edilen ekstraktlarının fenolik bileşik, antioksidan ve antimikrobiyal potansiyelleri araştııılmıştır. Fenolik bileşikler, yüksek performanslı sıvı kromatografisine bağlı elektrosprey iyonizasyon kütle spektrometresi (HPLC-DAD-ESI-MS ${ }^{\text {n }}$ ) kullanılarak belirlenmiştir. Ekstraktların antioksidan potansiyelleri DPPH ve ABTS metodları kullanılarak ayrıntılı olarak incelenmiştir. Örneklerin antimikrobiyal etkisi ise agar kuyu difuzyon yöntemi ile araştırılmıştır. Analizler sonucunda, örneklerde 22 adet fenolik bileşik tanımlanmış ve miktarları belirlenmiștir. Metanol ve etanol ekstraktlarında tanımlanan bileşik sayısının ve miktarının ayçiçek yağı, zeytinyağı ve su ekstraktlarına göre daha fazla olduğu belirlenmiştir. Antioksidan kapasite analiz sonuçlarında en yüksek içerik metanol ekstraktlarında ve en düşük içerik ise ayçiçek yağı ekstraktlarında saptanmıştır. Antimikrobiyal aktivite analiz sonuçları incelendiğinde ise sarı kantaron bitkisinin ayçicek yağı ve zeytinyağı ile hazırlanan ekstraktlarının Escherichia coli, Staphylococcus aeureus, Pseudomonas aeuroginasa mikroorganizmaları üzerinde inhibisyon etkisi gözlemlenmezken, metanol, etanol ve su ile hazırlanan ekstraktları antimikrobiyal etki göstermiştir. Test edilen mikroorganizmalara karşı en düşük antimikrobiyal aktivite, su ile hazırlanan bitki ekstraktında gözlemlenmiştir. Tüm sonuçlar genel olarak değerlendirildiğinde, etanol ve metanol ile hazırlanan ekstraktlarda tanımlanan fenolik bileşik sayısının ve miktarının daha fazla olduğu, antioksidan potansiyelin diğer ekstraktlara oranla daha yüksek olduğu saptanmıştır.

Anahtar Kelimeler: Sarı kantaron, Hypericum perfaratum L. fenolik bileşikler, antioksidan kapasite, agar kuyu difüzyon yöntemi, LC-DAD-ESI-MS/MS

\section{Characterization of Phenolics and Determination of Antioxidant and Antimicrobial Potential of St John's Wort (Hypericum perforatum L.) Plant}

\begin{abstract}
In this study, the phenolic compounds, antioxidant and antimicrobial potentials of St. John's Wort (Hypericum perforatum L.) extracts obtained using different solvents (ethanol, methanol, sunflower oil, olive oil and water) were investigated. Phenolic compounds were determined using high performance liquid chromatography coupled electrospray ionization mass spectrometry (HPLCDAD-ESI-MS ${ }^{n}$. The antioxidant potentials of the extracts were investigated in detail using DPPH and ABTS methods. The antimicrobial effect of the samples was investigated by agar well diffusion method. As a result of the analysis, 22 phenolic compounds were identified in the samples and their amounts were determined. It was determined that the number and amount of compounds identified in methanol and ethanol extracts were higher than sunflower oil, olive oil and water extracts. In the antioxidant capacity analysis results, the highest content was found in methanol extracts and the lowest content was found in sunflower oil extracts. When the antimicrobial activity analysis results were examined, no inhibition effect was observed on Escherichia coli, Staphylococcus aeureus, Pseudomonas aeuroginasa microorganisms, while the extracts prepared with methanol, ethanol and water showed an antimicrobial effect. The lowest antimicrobial activity against the tested

Yayın Kuruluna Geliş Tarihi: 24.09.2021

Kabul Tarihi: 24.12.2021

${ }^{1}$ Adana Alparslan Türkeş Bilim ve Teknoloji Üniversitesi, Gıda Mühendisliği Bölümü, Adana

${ }^{2}$ Çukurova Üniversitesi, Ziraat Fakültesi, Gıda Mühendisliği Bölümü Balcalı/ADANA

*E-posta:hkelebek@atu.edu.tr
\end{abstract}




\section{Sarı Kantaron (Hypericum perforatum L.) Fenoliklerinin Karakterizasyonu, Antioksidan ve Antimikrobiyal Potansiyelinin Belirlenmesi}

microorganisms was observed in the plant extract prepared with water. When all the results were evaluated in general, it was determined that the number and amount of phenolic compounds defined in the extracts prepared with ethanol and methanol were higher, and the antioxidant potential was higher than the other extracts.

Keywords: St. John's Wort, Hypericum perfaratum L., phenolic compounds, antioxidant capacity, agar well diffusion method, LC-DAD-ESI-MS/MS

ORCID ID (Yazar sırasına göre)

0000-0002-8419-3011, 0000-0003-0450-2668, 0000-0002-8419-3019

\section{Giriş}

Sar1 kantaron (Hypericum perforatum L.) Hypericum türleri içerisinde en yaygın olarak yetişen, sarı çiçekli, yaprakları sapsız, oval ve doğrusal, tüysüz, genellikle tabanda odunsu bir yapıya sahip çok yıllık bir bitkidir (Zou ve ark., 2004; Ernst, 2013). Yetiştiği bölgeye göre yara otu, bin bir delik otu, püren, kan otu, koyun kıran, kılıç otu, kuzu kıran ve mayasıl otu gibi isimlendirilen Hypericum perforatum L., dünyada St. John bitkisi olarak bilinmektedir. Dünyanın 1lıman ve tropikal bölgelerinde geniş bir dağ 11 ım gösteren bu bitki deniz seviyesinden 2500 m'ye kadar olan alanlarda doğal olarak yetişmektedir (Güner ve ark., 2000; Altan ve ark.,2015).

Hypericum cinsinin dünyada 400 civarında türü bulunmaktadır. Hypericum kökenli ilaçların kullanımı Avrupa'da büyük ölçüde tercih edilmektedir ve Amerika'da da her geçen gün artış görülmektedir (Kasper ve Dienel, 2002; Lecrubier ve ark., 2002).

Sarı kantaron ülkemizde Marmara, Karadeniz, Ege, Orta ve Doğu Anadolu, Akdeniz ve Güneydoğu Anadolu Bölgelerinde doğal olarak yetişmektedir. Ülkemiz Hypericum türleri bakımından önemli bir merkez olup mevcut 96 türün 46's1 endemik olarak yetişmektedir (Güner ve ark., 2000; Altan ve ark., 2015; Güner ve ark., 2012; Baytop, 1999).

Polifenoller grubu bileşikleri içerisinde yer alan flavonoidler ve fenolik asitler gibi birçok farklı fenolik bileşiğine sahip olduğu bildirilen Hypericum perforatum L., bu bileşiklerin sağladığı doğal antioksidan özellik sayesinde birçok çalışmaya konu olmuştur (Jürgenliemk ve Nahrstedt, 2002; Silvave ark., 2008). Ayrica birçok gıdanın oksidasyonunu önlemede önemli bir alternatif olan fenolik bileşikler bu bitkide önemli miktarlarda bulunmaktadır (SánchezMuniz ve ark., 2012; Becker ve ark., 2016).

Yapılan çalışmalarda özellikle zengin fenolik içeriğiyle sarı kantaronun açık yaralar, yanıklar, morarmalar, şişmeler gibi dermatolojik hastalıkların tedavisinde kullanıldığ bildirilmiştir (Saddiqe ve ark., 2010; Wölfle ve ark., 2014). Hypericum perforatum L. bitkisinden elde edilen ürünler klasik antidepresan ilaçların yerine ikame olarak kullanıldığında depresyon tedavisinin maliyetini önemli ölçüde düşürdüğü ifade edilmektedir (Solomon ve ark.,2013). Günümüzde sağlıklı yaşamak adına doğal olarak hazırlanmış bitkisel ürünlerin tüketimi uzun yıllardır insanların beslenmesinde yer almaktadır. Bitkisel ürünler aynı zamanda gida takviyesi olarak da tanımlanmaktadır. Gıdaların yararlı özellikleri (antioksidan, besinsel lif vb.) insanlar tarafından keşfedildikçe, gıda takviyelerinin sağlıklı olmak adına tüketimi her geçen gün artmaktadır (Atalay ve Erge, 2018).

Endemik türler başta olmak üzere Hypericum türünün birçoğunun doğal populasyonları hızla azalmaktadır. Bu nedenle ülkemiz için göz ardı edilen Hypericum türlerinin kimyasal bileşiklerinin tespit edilerek farmakolojik, kimyasal özelliklerinin ortaya konması ve kültüre alınarak hem korunmaları hem de seri üretilebilmeleri ile ilgili bilimsel çalışmalara ihtiyaç duyulmaktadır (Çırak ve Kurt, 2014 ). Sarı kantaron bitkisi farklı şekillerde (çay, yağ vb.) tüketilmekte olup ancak sarı kantaronun fenolik bileşik içeriklerini, antioksidan kapasitesini ve antimikrobiyal etkisini konu alan çalışmalar oldukça azdır.

$\mathrm{Bu}$ çalışmada, sarı kantaron (Hypericum perforatum L.) bitkisinin farkl1 solventler (etanol, metanol, ayçiçek yağı, zeytinyağı ve su) 


\section{Sarı Kantaron (Hypericum perforatum L.) Fenoliklerinin Karakterizasyonu, Antioksidan ve Antimikrobiyal Potansiyelinin Belirlenmesi}

kullanılarak elde edilen ekstraktlarının fenolik bileşik profilleri ayrıntılı olarak karakterize edilerek, antioksidan ve antimikrobiyal etkileri araştırılmıştır.

\section{Materyal ve Yöntem Materyal}

$\mathrm{Bu}$ çalışmada kullanılan kantaron bitkileri 8 Haziran 2019 tarihinde Adana ilinin Pozant1 ilçesinin Akçatekir Yaylası'ndan (doğal olarak yetişen Hypericum perfaratum L. bitkisinin taze çiçekli bitkileri) bitkilerin çiçeklenme dönemlerinde temin edilmiştir.

Metanol (HPLC grade), formik asit, sodyum karbonat ve hidroklorik asit Merck (Darmstat, Almanya) firmasından; gallik asit, $p$-kumarik asit, ferulik asit, protokateşik asit, klorojenik asit, epikateşin, kuersetin, Folin-Ciocalteu, kafeik asit ve o-kumarik asit Sigma Chemical Co. (St. Louis, ABD) firmasindan temin edilmiştir. DPPH (2,2-diphenyl-1Picrylhydrazyl), ABTS [2,2 -azinobis-(3-etilbenzotiazolin-6-sülfonik asit)] ve Troloks ((+/-)6-hidroksi-2,5,7,8-tetrametil-chroman-2-

karboksilik asid) Sigma-Aldrich Chemical Co. (St. Louis, ABD) firmasindan ve etanol Riedel de Haen Co. (Seelze, Almanya) firmasindan temin edilmiştir. HPLC ve LC-MS/MS analizlerinde mobil fazların hazırlanmasında Elga Purelab Option-Q marka saf su cihazından sağlanan $18.2 \mathrm{M} \Omega-\mathrm{cm}$ ultra saf su kullanılmıştır. Standart çözeltiler ve diğer hassas çözeltiler günlük olarak hazırlanmıştır.

Kantaron bitkisi örneklerinde ekstraksiyon öncesinde $45^{\circ} \mathrm{C}^{\prime}$ de etüvde sabit ağırlığa ulaşıncaya kadar kurutma işlemi yapılmıştır. Kurutulmuş kantaron bitkileri daha sonra öğütülerek zeytinyağı, ayçiçek yağı, metanol, etanol ve su kullanilarak ultrasonik su banyosunda ekstraksiyonlar hazırlanmıştır (Şekil 1.). Sarı kantaron örneklerinde toplam fenolik madde analizleri, fenolik bileşik analizleri, antioksidan aktivite analizleri, antimikrobiyal aktivite analizleri gerçekleştirilmiştir.

\section{Yöntem}

\section{Toplam Fenolik Madde Analizi}

Sarı kantaron bitkisinde toplam fenolik madde analizi, Saafi ve ark. (2009)'nın uyguladıkları yöntemde bazı değişiklikler yapılarak gerçekleştirilmiştir. Elde edilen ekstraktlar seyreltilmiş ve seyreltilen örneklerden $100 \mu 1$ alınarak üzerine $0.5 \mathrm{ml}$ Folin-Ciocalteu çözeltisi (1/10 oranında saf su ile seyreltilmiş) ilave edilerek 5 dakika bekletilmiştir. Daha sonra bu karışıma \%20'lik sodyum bikarbonat ilave edilmiş ve 90 dakika bekleme sonrası UV-Vis spektrofotometre (Agilent Carry 60) ile 765 nm'de absorbans değerleri okunmuştur. Toplam fenolikler, farklı konsantrasyonlarda hazırlanan $(5,10,25,50,100,250,500 \mathrm{ppm})$ gallik asit standartlarının aynı yöntemle belirlenen absorbanslarından elde edilen kalibrasyon eğrisi ile hesaplanmıştır (Aydin ver ark., 2021).

Fenolik Bileşiklerin LC-MS/MS ile Analizleri Farkl1 solventler kullanilarak elde edilen ekstraktlarda fenolik bileşikler oldukça hassas bir yöntem olan LC-MS/MS ile tanımlanmıştır. Sarı kantaron ekstraktlarının fenolik bileşik analizleri Kelebek ve ark. (2020) yöntemine göre gerçekleştirilmiştir. Elde edilen ekstraktlar $0.45 \mu \mathrm{m}$ 'lik membran filtrelerden geçirilerek LC'ye enjekte edilerek fenolik bileşik profilleri belirlenmiştir. $\mathrm{Bu}$ ekstraktlar ayrıca antioksidan kapasite analizlerinde ve antimikrobiyal analizlerde de kullanılmıştır.

\section{Antioksidan Kapasite Analizleri}

Sar1 kantaron örneklerinin antioksidan aktiviteleri DPPH ve ABTS yöntemleriyle belirlenmiștir. Serbest radikalleri önleme yeteneğini ölçebilen DPPH (2,2-difenil-1-pikri hidrazil) kullanılarak ve metanol içerisinde gerçekleşen reaksiyonun zamana karş1 değişiminin $515 \mathrm{~nm}$ 'de UV-Vis (Agilent-Cary 60) spektrofotometredeki ölçüm sonuçlarına göre değerlendirilmiştir (Brand-Williams ve ark., 1995; Kelebek ve ark., 2009). Elde edilen absorbans değerleri Trolox standart eğim çizelgesi ile hesaplanmıştır. 


\section{Sarı Kantaron (Hypericum perforatum L.) Fenoliklerinin Karakterizasyonu, Antioksidan ve Antimikrobiyal Potansiyelinin Belirlenmesi}

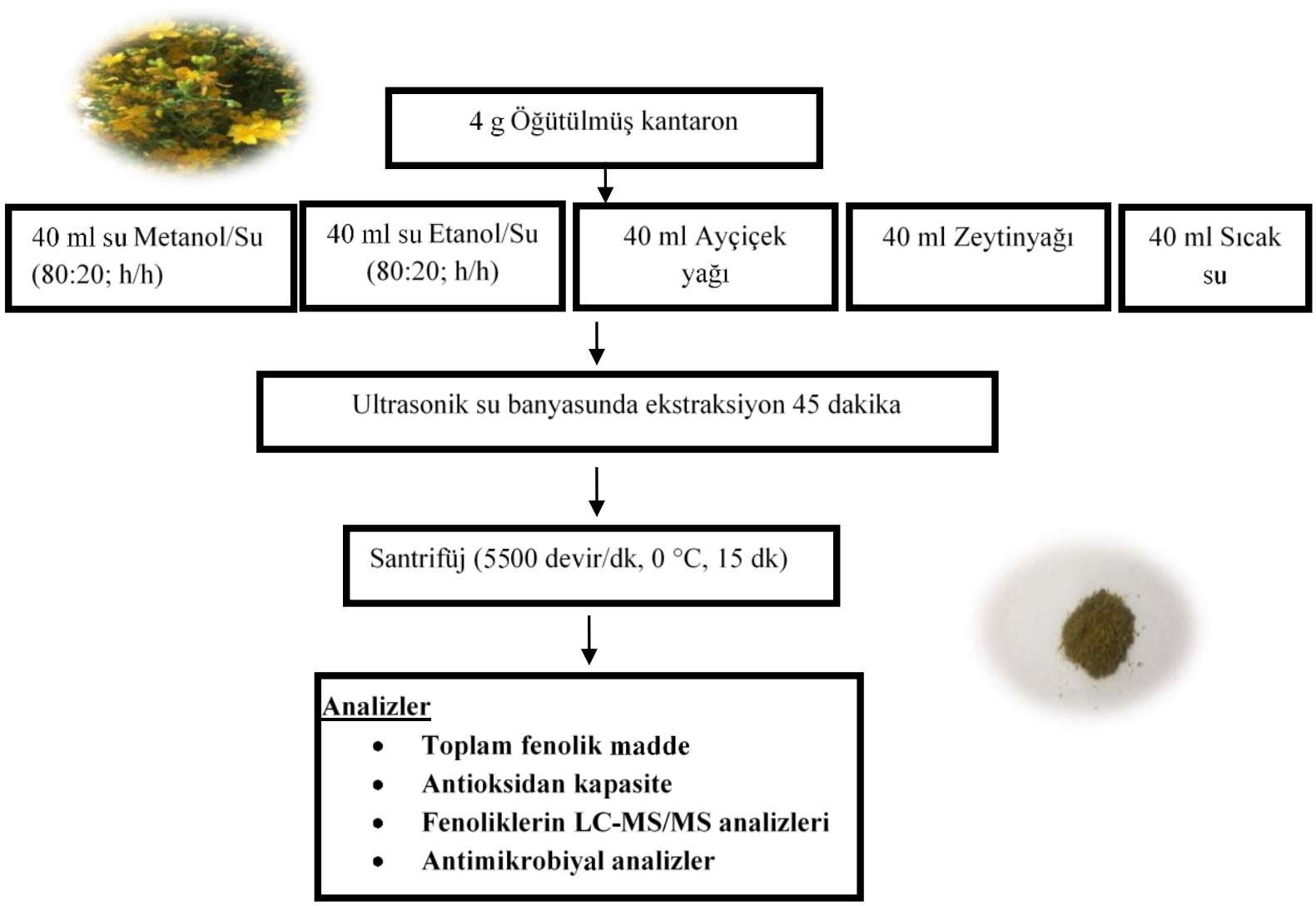

Şekil 1. Analizlerde kullanılan ekstraktların hazırlanma aşamaları

\section{Antimikrobiyal Aktivite Analizleri}

Sarı kantaron ekstraktlarının antimikrobiyal aktiviteleri agar kuyu difüzyon yöntemi kullanılarak belirlenmiştir. Antimikrobiyal aktivite analizlerinde Staphylococcus aureus ATCC 29213, Escherichia coli ATCC 25922 ve Pseudomonasaeuroginasa ATCC 27853 bakterileri test mikroorganizmaları olarak kullanılmıștır. $\mathrm{Bu}$ bakteriler triptik soy agar üzerinde $35^{\circ} \mathrm{C}^{\prime} \mathrm{de} \quad 18-24$ saat inkübasyon sonunda aktifleştirilerek ve bakteri çözeltisinin bulanıklığg $0.5 \mathrm{McF}$ arland birimi olacak şekilde $\% 0,9$ konsantrasyonda steril tuzlu su çözeltisi kullanılarak ayarlanmıştır ve takiben 1:10 ya da 1:100 oranında sulandırılarak $10^{6} \mathrm{KOB} / \mathrm{ml}$ elde edilecek şekilde ayarlanmıştır. $0.5 \mathrm{McF}$ arland birimine denk olan bakteri sayısı triptik soy agar besiyerine ekim yapilarak ve $35^{\circ} \mathrm{C}$ ' de $18-24$ saat inkübasyon sonucunda belirlenmiștir. Bakteri kültürleri $\% 1$ oranında olacak şekilde 45- $50^{\circ} \mathrm{C}$ 'ye soğutulan Muller Hinton Agar içerisine inokule edilerek ve steril plakalar içerisine dökülmüştür. Ekstraktlar $0.22 \mu \mathrm{m}$ gözenek çapındaki membran filtrelerden geçirilerek ve 50 $\mu 1$ alınarak katılaşan besiyeri üzerinde açılan 7-8 mm çapında açılan kuyucuklar içerisine eklenmiştir. $35^{\circ} \mathrm{C}^{\prime}$ de 24 saatlik inkübasyon sonunda kuyucuk etrafinda oluşan zon çapları ölçülmüștür (Öztürk ve ark. 2015). Analizlerde pozitif kontrol olarak kloramfenikol, negatif kontrol olarak steril su kullanılmıştır. Tüm test mikroorganizmalarına karşı yapılan antimikrobiyal aktivite deneyleri üç tekerrürlü gerçekleştirilmiştir.

\section{Sonuçların Değerlendirilmesi ve İstatistiksel Analizler \\ Farklı yöntemler kullanılarak ekstraksiyonu hazırlanan sarı kantaron bitkisinin analiz sonuçları uluslararası literatürlerle karşılaştırılmış ve elde edilen veriler, SPSS 20}




\section{Sarı Kantaron (Hypericum perforatum L.) Fenoliklerinin Karakterizasyonu, Antioksidan ve Antimikrobiyal Potansiyelinin Belirlenmesi}

paket programı (SPSS Inc., Chicago, Illinois, USA) yardımıyla \%95 güven seviyesinde $(p \leq 0.05)$ varyans analizine tabi tutulmuş ve Duncan çoklu karşılaştırma testine göre, önemli

\section{Bulgular ve Tartışma}

Sarı Kantaron Bitkisinin Toplam Fenolik Madde Miktarları

Sar1 kantaron bitkisinin toplam fenolik madde miktarının 93,88-29,44 $\mathrm{mg} / 100 \mathrm{~g}$ arasında olduğu belirlenmiştir. Örneklerin toplam fenolik madde miktarları ve antioksidan aktiviteleri Şekil 2' de verilmiştir. Solventlere bağlı olarak oluşan farkl11ıklar istatistiksel yönden önemli bulunan farklılıklar incelenmiștir. Ayrıca, XLSTAT 2015 (Addinsoft, New York City, NY, USA) paket programı kullanılarak verilere temel bileșen analizleri uygulanmıştır.

$(p<0.05)$ bulunmuştur. En yüksek içerik $(93,88$ $\mathrm{mg} / 100 \mathrm{~g})$ metanol kullanılarak elde edilen ekstraktlarda saptanmıştır. Bunu miktarsal olarak etanol ile elde edilen ekstrakt $(81,27$ $\mathrm{mg} / 100 \mathrm{~g}$ ) izlemiştir. En düşük içerik ise su ile elde edilen ekstraktlarda saptanmıştır. Örnekler kıyaslandığında tespit edilen toplam fenolik madde miktarındaki azalma etanol ile elde edilen ekstraktlarda \%14 oranında ve ayçiçek yağı ile elde edilen ekstraktlarda \%68 civarında olmuştur.

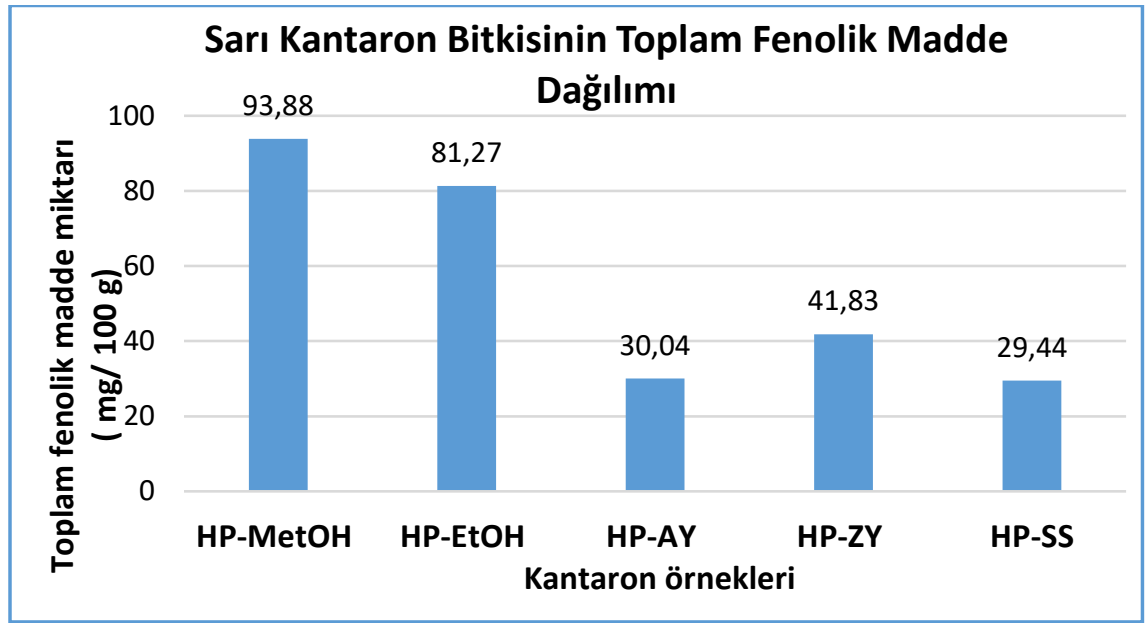

Şekil 2. Sarı kantaron bitkisinin toplam fenolik madde dağılımı

(MetOH; metil alkol, EtOH; etil alkol, AY; Ayçiçek yağı, ZY; Zeytin yağı, SS; Sicak su)

Çalıșmamızda elde edilen sonuçlar Raziq ve ark. (2011) çalışmasındaki sonuçlar ile miktarsal olarak benzerlik göstermese de solventler bakımından benzerlik (en yüksek miktarı saf metanol $7512 \mathrm{mg} / \mathrm{g}$, en düşük miktarı ise su ile elde edilen ekstraktlarda $2135 \mathrm{mg} / \mathrm{g}$ ) göstermektedir. Marrelli ve ark. (2014) İtalya'da dört farklı yükseklikten toplanan Hypericum perforatum $\mathrm{L}$. örneğinin toplam fenolik madde miktarının $27.87 \mathrm{mg} / \mathrm{g}-41.77 \mathrm{mg} / \mathrm{g}$ arasında değiştiğini bildirmişlerdir. Chimshirova ve ark. (2019) yaptıkları bir çalışmada Hypericum perfaratum ekstraktlarındaki toplam fenoliklerin $10,20 \quad-53,84 \quad \mathrm{mg} / \mathrm{g}$ arasında değiştiğini bildirmișlerdir. Yapılan çalıșmalar sonucunda sar1 kantaron bitkisinin toplam fenolik madde miktarlar1 200 mg GAE/g (Parzhanova ve ark., 2018), 181,02 mg GAE/g (Sarıürkçü ve ark.,2020), 265.43 g/kg (Seyrekoğlu ve Temiz 2020), $191 \mathrm{~g} / \mathrm{kg}$ (Skerget ve ark. 2005) olarak bildirilmiștir.

\section{Sarı Kantaron Bitkisinin Fenolik Bileşimlerindeki Değişim}

Sarı kantaron bitkisinde altısı klorojenik asit, ikisi flavanol, üçü fenolik asit, ikisi naphthodianthronlar ve dokuzu flavonoidler olmak üzere toplamda 22 adet bileşik tanımlanmış ve miktarları belirlenmiştir. $\mathrm{Bu}$ 


\section{Sarı Kantaron (Hypericum perforatum L.) Fenoliklerinin Karakterizasyonu, Antioksidan ve Antimikrobiyal Potansiyelinin Belirlenmesi}

bileşiklerin toplam miktarı 37.63-85,55 $\mathrm{mg} / \mathrm{g}$ arasında değişmiştir. Sarı kantaron bitkisinin

fenolik bileşiklerinin dağılımları Şekil 3'de verilmiştir.

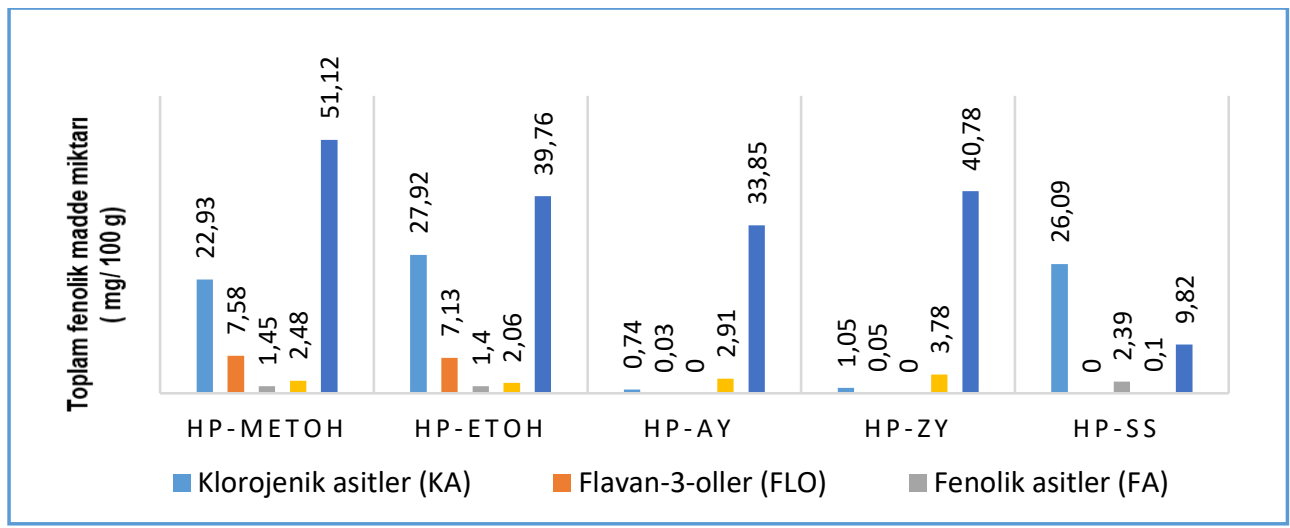

Şekil 3. Sarı kantaron bitkisinin fenolik bileşiklerinin dağılımları

(MetOH; metil alkol, EtOH; etil alkol, AY; Ayçiçek yağı, ZY; Zeytin yağı, SS; Sicak su)

Sar1 kantaron bitkisine ait LC-MS/MS ile kaydedilen kromatogramlar ve spektrumlar Şekil 4 ve Şekil 5'de verilmiştir. Orhan ve Kartal (2015) sarı kantaronda çalışmamıza benzer şekilde klorojenik asit, rutin, hiperozit, kersitrin, kuersetin ve biapigenin, psödohiperisin, hiperisin, hiperforin ve adhiperforin bileşiklerini tanımlamışlardır.

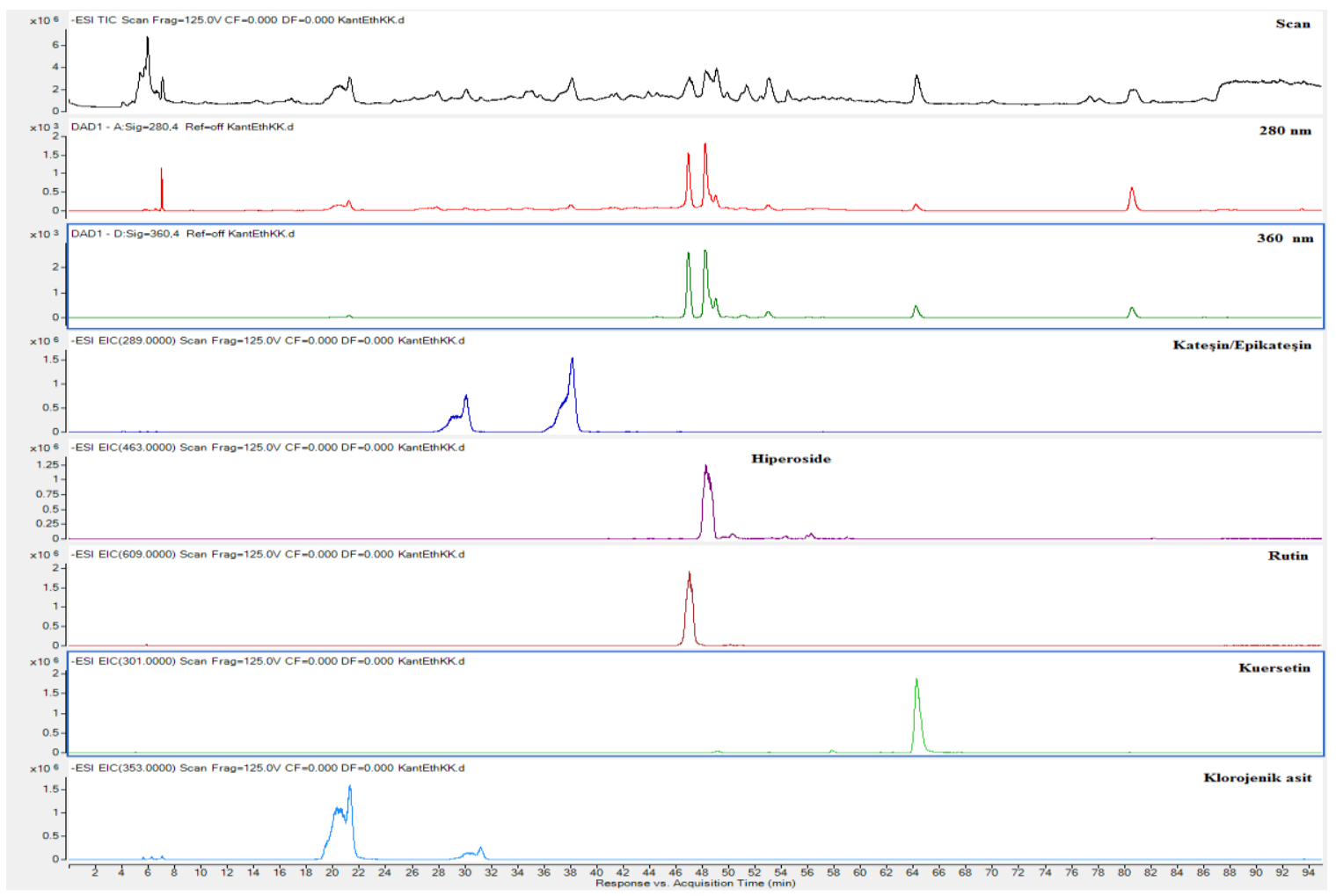

Şekil 4. Sarı kantaron bitkisine ait LC-MS/MS ile kaydedilen kromatogramlar 


\section{Sarı Kantaron (Hypericum perforatum L.) Fenoliklerinin Karakterizasyonu, Antioksidan ve Antimikrobiyal Potansiyelinin Belirlenmesi}

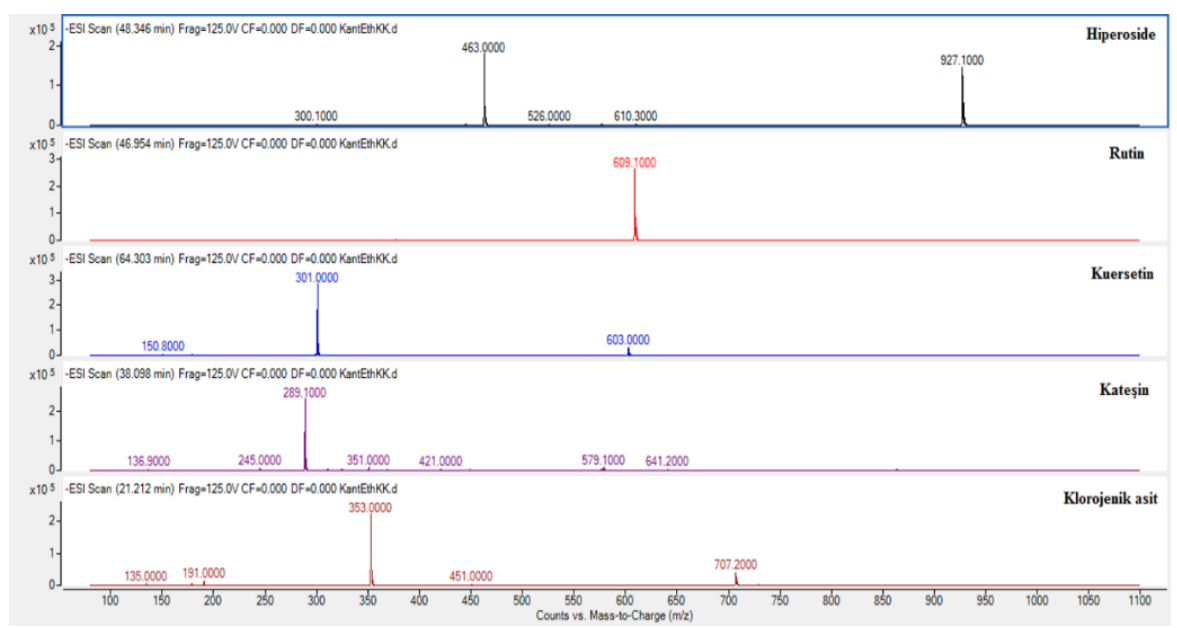

Şekil 5. Sarı kantaron bitkisinde belirlenen bazı bileşiklere ait LC-MS/MS ile kaydedilen spektrumlar

Neoklorojenik asit klorojenik asitler arasinda baskın olan bileşik olarak tanımlanmıştır (Tablo 1). Bu bileşiğin miktarı etanol ile elde edilen ekstraktlarda en yüksek $(14,26 \mathrm{mg} / \mathrm{g})$ olarak saptanmış ve bunu sırasılyla metanol $(12,59$ $\mathrm{mg} / \mathrm{g})$, sicak su $(11,68 \mathrm{mg} / \mathrm{g})$, ayçiçek $(0,67$ $\mathrm{mg} / \mathrm{g})$ ve zeytinyağ $(0,65 \mathrm{mg} / \mathrm{g})$ ile hazırlanan ekstraktlar izlemiştir. Solventlere bağlı olarak oluşan farklılıklar istatistiksel yönden önemli $(p<0.05)$ bulunmuştur. İnsanların beslenmesinde klorojenik asit oldukça fazla yer almakta olup birçok çalışmada antioksidan ve antibakteriyel etki gösterdiği bildirilmiştir (Kang ve Lee, 2014). Farklı çalışmalarda, klorojenik asit ve kuersetinin fenoliklerin yara iyileşmesini hızlandırdığı bildirilmiştir (Chen ve ark. 2013, Almeida ve ark. 2011, Gopalakrishnan ve ark. 2016).

Çalışmada flavanol grubu bileşiklerden kateşin $(289 \mathrm{~m} / \mathrm{z})$ ve epikateşin $(289 \mathrm{~m} / \mathrm{z})$ olmak üzere iki adet bileşik belirlenmiştir. Bu bileşikler su ile hazırlanan ekstraktlarda belirlenmezken metanol ve etanol ile hazırlanan ekstraktlarda toplam miktarları sirasiyla $7,58 \mathrm{mg} / \mathrm{g}$ ve $7,13 \mathrm{mg} / \mathrm{g}$ olarak tespit edilmiştir.

Sarı kantaron bitkisinden su, etanol ve metanol ile elde edilen ekstraktlardan fenolik asit yapısında kafeik asit $(179 \mathrm{~m} / \mathrm{z})$, protokateşik asit $(153 \mathrm{~m} / \mathrm{z})$ ve ferulik asit $(193 \mathrm{~m} / \mathrm{z})$ olmak üzere 3 adet fenolik asit tanımlanmıştır. Fenolik asitlerin toplam miktarı ayçiçek ve zeytinyağı ile elde edilen ekstraktlarda saptanmazken diğer ektraktlarda 1.40 ile $2.30 \quad \mathrm{mg} / \mathrm{g}$ arasında değişmiştir (Tablo 1). Fenolik asitler içerisinde baskın olan bileşik kaffeik asit olarak saptanmış ve bunu ferulik ve protokateşik asit izlemiştir. Hosni ve ark. (2010) Tunus'ta $H$. perforatum, $H$. perfoliatum ve $H$. ericoides türlerinin metanolik ekstraktlarında RP-HPLC-DAD yöntemiyle tanımladıkları 15 adet fenolik bileşik arasında $H$. perforatum ekstraktında $0,7 \mathrm{mg} / \mathrm{g}$ düzeyinde ferulik asit tespit etmişlerdir. Bizim çalışmamızda da metanolik ekstraktlarda 0,54 $\mathrm{mg} / \mathrm{g}$ ferulik asit saptanmış olup Hosni ve ark. (2010)'nın çalışmasındaki bulgulara yakın sonuç elde edilmiştir.

Sar1 kantaron bitkisinden ekstraklarından naftodiantronlar grubundan hiperisin $(503,5 \mathrm{~m} / \mathrm{z})$ ve protohiperisin $(505,6 \mathrm{~m} / \mathrm{z})$ olmak üzere iki bileşik belirlenmiştir. Bu bileşikler Hypericum cinsine ait olan tipik bileşiklerdir. Bitkinin yoğun kırmızı renginden ve fototoksik özelliklerinden sorumludur. Bu gruptaki en önemli bileşik hiperisinlerdir. Zeytinyağı ile hazırlanan ekstraktlarda en yüksek içerik ve su ile hazırlanan örneklerde ise en düşük içerik saptanmiştır.

Sarı kantaron ekstraktlarında flavonoidler temel biyoaktif bileşenler olarak saptanmıştır. $\mathrm{Bu}$ bileşiklerin miktarı 9,82 ile 51,12 mg/g arasında 


\section{Sarı Kantaron (Hypericum perforatum L.) Fenoliklerinin Karakterizasyonu, Antioksidan ve Antimikrobiyal Potansiyelinin Belirlenmesi}

değişmiştir (Tablo1). Toplam flavonoid miktarı metanol>zeytinyağı $>$ etanol $>$ ayçiçek $\quad$ yağ $1>$ su ekstraktları şeklinde sıralama göstermiştir. Kullanilan solventler toplam flavonoid bileşikleri miktarını istatistiksel olarak önemli $(p<0.05)$ ölçüde değiştirmiştir. Bu bileşiklerden sarı kantaron bitkisinde en yüksek miktarda rutin, daha sonra kuersetin-3-b-Dgalaktopiranozit (Hiperoside), kuersetin-3-b-Dglukopiranozit (isokuersitrin) bileşikleri tespit edilmiştir. Metanol ekstraktı ile yapılan analiz sonuçlarına göre flovanoidlerden rutin 15,06 $\mathrm{mg} / \mathrm{g}$ ve kuersetin-3-b-D-galaktopiranozit (Hiperosid) 12,48 $\mathrm{mg} /$ golarak saptanmıştır. Kantaron bitkisinde rutin ve hiperozit bileşikleri temel flavonoidler olarak bildirilmiștir (Altan ve ark., 2015). Rutin bileşiğinin antioksidan ve antibakteriyel etkisinin olduğu bildirilmiștir. Zdunic ve ark., (2017) tarafindan yapılan bir çalışmada sarı kantaronun etanolik ekstraklarında baskın olan grubu çalışmamızda olduğu gibi flavonoidler oluşturmuş olup toplam $52,3 \mathrm{mg} / \mathrm{g}$ olarak tespit edilmiştir. Silva ve ark. (2005) Hypericum perforatum L bitkisinin etanolik ekstraktlarının hiperisin, hiperforin ve türevleri, rutin, hiperozid, kuersetin, flavonoller ve flavonlar içerdiğini, bu bileşiklerin önemli bir antioksidan kaynağı olabileceğini bildirmişlerdir.

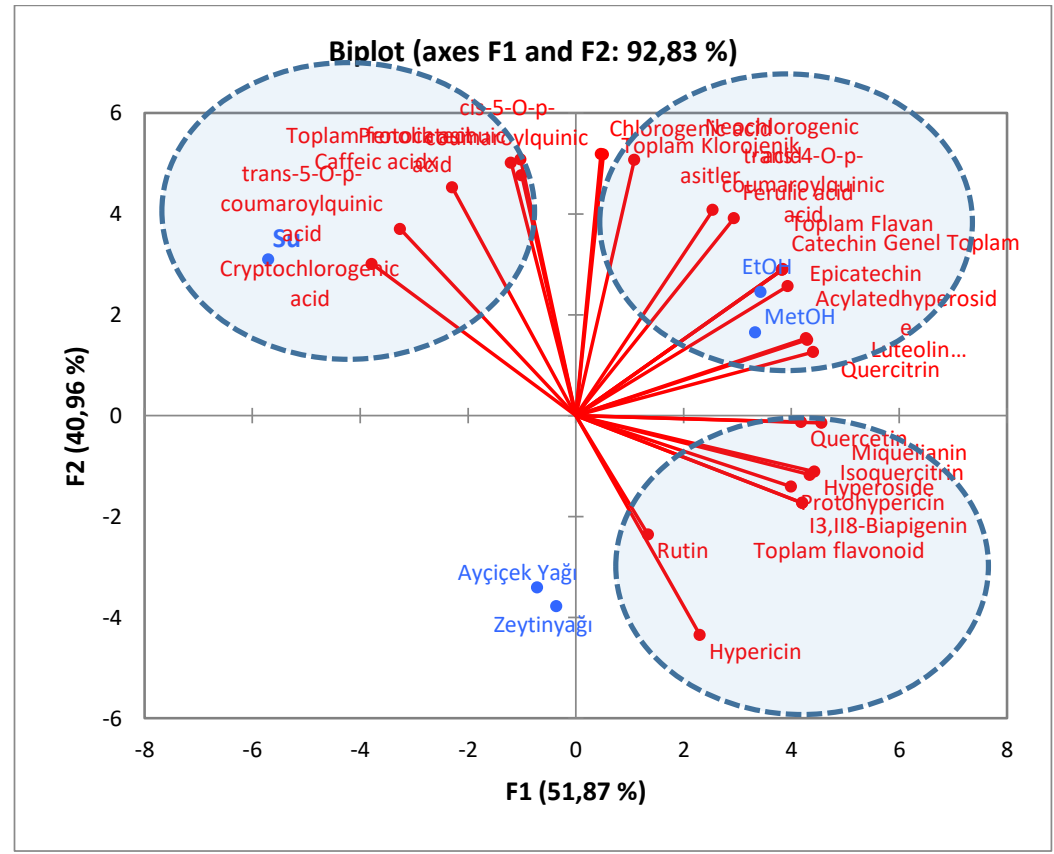

Şekil 6. Fenolik bileşikler için temel bileşen analiz (PCA) sonuçları

Farklı solventler ile hazırlanan ekstraktların fenolikler bakımından sınıflandırılmasında temel bileşen analizleri (PCA) kullanılmıştır. Fenolik bileşikler için PCA modeli, toplam varyansın \%92,83'ünü açiklayan üç temel bileșenle oluşturulmuştur (Şekil 6). PC1 \%51,87 ve PC2 toplam varyansın $\% 40,96$ 'sını oluşturmuştur. Analizlerde üç temel grup oluşmuştur. Grafiğin sol üst tarafı su ile elde edilen ekstraktı içermektedir. Bu grup trans-5-O-p-kumarilkuinik asit, cis-5-O-p-kumarilkuinik asit, toplam fenolik asit, kriptoklorojenik asit, kaffeik ve protokateşik asit ile karakterize olmuştur. Grafiğin sağ üst tarafinda ise etanol ve metanol ile elde edilen ekstraktlar grup oluşturmuştur. $\mathrm{Bu}$ grup klorojenik asit, neoklorojenik asit, toplam klorojenik asit, kateşin, epikateşin, ferulik asit, trans4-O-p-kumarilkuinik asit, luteolin heksozit ve kuersitrin ile karakterize olmuştur. Şekil 6'nın sağ alt kısmında ise yağ ile elde edilen ekstraktlar toplanmış ve bu grup hiperosit, rutin, hiperisin, kuersetin, izokuersitrin ve toplam flavonidlerce karakterize olmuştur. 


\section{Sarı Kantaron (Hypericum perforatum L.) Fenoliklerinin Karakterizasyonu, Antioksidan ve Antimikrobiyal Potansiyelinin}

\section{Belirlenmesi}

Tablo 1. Sarı Kantaron bitkisinin fenolik bileşimleri (mg/g)

\begin{tabular}{|c|c|c|c|c|c|c|c|c|}
\hline Bileşikler & $\begin{array}{l}\text { Molekül } \\
\text { formülüi }\end{array}$ & {$[\mathrm{M}-\mathrm{H}]$} & MS/MS iyonları & $\begin{array}{c}\text { HP-MetOH } \\
\text { Ekstraktı }\end{array}$ & $\begin{array}{c}\text { HP-EtOH } \\
\text { Ekstraktı }\end{array}$ & $\begin{array}{c}\text { HP-AY } \\
\text { Ekstraktı }\end{array}$ & $\begin{array}{c}\text { HP-ZY } \\
\text { Ekstaktı }\end{array}$ & $\begin{array}{c}\text { HP-Su } \\
\text { Ekstaktı }\end{array}$ \\
\hline \multicolumn{9}{|l|}{ Klorojenik asitler $(\mathrm{KA})$} \\
\hline Neoklorojenik asit(trans-5-O-Kaffeilkuinik asit) & $\mathrm{C}_{16} \mathrm{H}_{18} \mathrm{O}_{9}$ & 353 & $191,179,135$ & $12,59 \pm 0,52^{\mathrm{b}}$ & $14,26 \pm 0,59^{\mathrm{a}}$ & $0,67 \pm 0,03^{\mathrm{d}}$ & $0,65 \pm 0,03^{\mathrm{d}}$ & $11,68 \pm 0,49^{\mathrm{c}}$ \\
\hline Klorojenik asit(3-O- Kaffeilkuinik asit ) & $\mathrm{C}_{16} \mathrm{H}_{18} \mathrm{O}_{9}$ & 353 & 191 & $6,85 \pm 0,36^{\mathrm{b}}$ & $8,11 \pm 0,43^{\text {a }}$ & $0,05 \pm 0,00^{\mathrm{c}}$ & $0,37 \pm 0,02^{\mathrm{c}}$ & $7,79 \pm 0,32^{a}$ \\
\hline Kriptoklorojenik asit(4-O- Kaffeilkuinik asit ) & $\mathrm{C}_{16} \mathrm{H}_{18} \mathrm{O}_{9}$ & 353 & $191,173,135$ & $0,16 \pm 0,01^{\mathrm{b}}$ & $0,19 \pm 0,01^{\mathrm{b}}$ & $0,00 \pm 0,00^{\mathrm{c}}$ & $0,01 \pm 0,00^{\mathrm{c}}$ & $2,96 \pm 0,12^{\mathrm{a}}$ \\
\hline trans 4-O-p-Kumaroylkuinik asit & $\mathrm{C}_{16} \mathrm{H}_{18} \mathrm{O}_{8}$ & 337 & $191,173,163,155$ & $2,50 \pm 0,13^{\mathrm{b}}$ & $4,46 \pm 0,23^{\text {a }}$ & $0,01 \pm 0,00^{\mathrm{d}}$ & $0,01 \pm 0,00^{\mathrm{d}}$ & $1,45 \pm 0,06^{\mathrm{c}}$ \\
\hline cis 5-O-p-Koumaroylkuinik asit & $\mathrm{C}_{16} \mathrm{H}_{18} \mathrm{O}_{8}$ & 337 & $191,173,163,155,137$ & $0,59 \pm 0,03^{\mathrm{b}}$ & $0,64 \pm 0,03^{\mathrm{b}}$ & $0,00 \pm 0,00^{\mathrm{c}}$ & $0,00 \pm 0,00^{\mathrm{c}}$ & $0,98 \pm 0,04^{\mathrm{a}}$ \\
\hline trans 5-O-p-Kumaroylkuinik asit & $\mathrm{C}_{16} \mathrm{H}_{18} \mathrm{O}_{8}$ & 337 & $191,173,163,155,137$ & $0,24 \pm 0,01^{\mathrm{b}}$ & $0,26 \pm 0,01^{b}$ & $0,00 \pm 0,00^{c}$ & $0,00 \pm 0,00^{c}$ & $1,24 \pm 0,05^{\mathrm{a}}$ \\
\hline Toplam KA & & & & $22,93 \pm 1,07^{\mathrm{c}}$ & $27,92 \pm 1,31^{\text {a }}$ & $0,74 \pm 0,03^{\mathrm{d}}$ & $1,05 \pm 0,04^{\mathrm{d}}$ & $26,09 \pm 1,09^{\mathrm{b}}$ \\
\hline \multicolumn{9}{|l|}{ Flavan-3-oller (FLO) } \\
\hline Kateşin* & & 289 & $245,205,179$ & $2,54 \pm 0,13^{\mathrm{a}}$ & $2,49 \pm 0,13^{\mathrm{a}}$ & $0,01 \pm 0,00^{\mathrm{b}}$ & $0,02 \pm 0,00^{\mathrm{b}}$ & $0,00 \pm 0,00^{\mathrm{b}}$ \\
\hline Epikateşin* & & 289 & $245,205,179$ & $5,04 \pm 0,27^{\mathrm{a}}$ & $4,63 \pm 0,24^{\mathrm{b}}$ & $0,02 \pm 0,00^{\mathrm{c}}$ & $0,03 \pm 0,00^{\mathrm{c}}$ & $0,00 \pm 0,00^{\mathrm{c}}$ \\
\hline Toplam FLO & & & & $7,58 \pm 0,40^{\mathrm{a}}$ & $7,13 \pm 0,38^{b}$ & $0,03 \pm 0,00^{c}$ & $0,05 \pm 0,00^{c}$ & $0,00 \pm 0,00^{c}$ \\
\hline \multicolumn{9}{|l|}{ Fenolik asitler (FA) } \\
\hline Kaffeik asit & $\mathrm{C}_{9} \mathrm{H}_{8} \mathrm{O}_{4}$ & 179 & 135 & $0,73 \pm 0,04^{\mathrm{c}}$ & $0,85 \pm 0,04^{\mathrm{b}}$ & $0,00 \pm 0,00^{\mathrm{d}}$ & $0,00 \pm 0,00^{\mathrm{d}}$ & $2,01 \pm 0,08^{\mathrm{a}}$ \\
\hline Protokateșik asit & $\mathrm{C}_{7} \mathrm{H}_{6} \mathrm{O}_{4}$ & 153 & 109 & $0,18 \pm 0,01^{\mathrm{b}}$ & $0,10 \pm 0,01^{\mathrm{c}}$ & $0,00 \pm 0,00^{\mathrm{d}}$ & $0,00 \pm 0,00^{\mathrm{d}}$ & $0,22 \pm 0,01^{\mathrm{a}}$ \\
\hline Ferulik asit & $\mathrm{C}_{10} \mathrm{H}_{10} \mathrm{O}_{4}$ & 193 & 134 & $0,54 \pm 0,03^{\mathrm{a}}$ & $0,45 \pm 0,02^{b}$ & $0,00 \pm 0,00^{\mathrm{d}}$ & $0,00 \pm 0,00^{\mathrm{d}}$ & $0,17 \pm 0,01^{\mathrm{c}}$ \\
\hline Toplam FA & & & & $1,45 \pm 0,08^{\mathrm{b}}$ & $1,40 \pm 0,07^{\mathrm{b}}$ & $0,00 \pm 0,00^{c}$ & $0,00 \pm 0,00^{c}$ & $2,39 \pm 0,10^{\mathrm{a}}$ \\
\hline \multicolumn{9}{|l|}{ Naftodiantronlar (Naft) } \\
\hline Hiperisin & $\mathrm{C}_{30} \mathrm{H}_{16} \mathrm{O}_{8}$ & 503,5 & - & $2,16 \pm 0,11^{\mathrm{c}}$ & $1,69 \pm 0,09^{\mathrm{d}}$ & $2,55 \pm 0,11^{\mathrm{b}}$ & $3,57 \pm 0,15^{\mathrm{a}}$ & $0,07 \pm 0,00^{\mathrm{e}}$ \\
\hline Protohiperisin & $\mathrm{C}_{30} \mathrm{H}_{18} \mathrm{O}_{8}$ & 505,6 & - & $0,32 \pm 0,02^{\mathrm{b}}$ & $0,37 \pm 0,02^{\mathrm{a}}$ & $0,36 \pm 0,01^{\mathrm{a}}$ & $0,21 \pm 0,01^{\mathrm{c}}$ & $0,03 \pm 0,00^{\mathrm{d}}$ \\
\hline Toplam Naph & & & & $2,48 \pm 0,13^{\mathrm{c}}$ & $2,06 \pm 0,11^{\mathrm{d}}$ & $2,91 \pm 0,12^{\mathrm{b}}$ & $3,78 \pm 0,16^{\mathrm{a}}$ & $0,10 \pm 0,00^{\mathrm{e}}$ \\
\hline \multicolumn{9}{|l|}{ Flavonoidler (FLV) } \\
\hline Kuersetin-3-b-D-galakto piranozit (Hiperoside) & $\mathrm{C}_{21} \mathrm{H}_{20} \mathrm{O}_{12}$ & 463 & 301 & $12,48 \pm 0,66^{\mathrm{b}}$ & $14,02 \pm 0,74^{\mathrm{a}}$ & $9,29 \pm 0,39^{\mathrm{c}}$ & $11,72 \pm 0,49^{\mathrm{b}}$ & $2,79 \pm 0,12^{\mathrm{d}}$ \\
\hline Kuersetin-3-b-D-gluko piranozit (İsoquercitrin) & $\mathrm{C}_{21} \mathrm{H}_{20} \mathrm{O}_{12}$ & 463 & 301 & $9,05 \pm 0,48^{\mathrm{b}}$ & $10,46 \pm 0,55^{\mathrm{a}}$ & $6,45 \pm 0,27^{\mathrm{c}}$ & $9,00 \pm 0,38^{b}$ & $1,65 \pm 0,07^{\mathrm{d}}$ \\
\hline Kuersetin -3-b-D-glukuro piranozit (Miquelianin) & $\mathrm{C}_{21} \mathrm{H}_{18} \mathrm{O}_{13}$ & 477 & 301 & $4,45 \pm 0,23^{\mathrm{a}}$ & $3,78 \pm 0,20^{\mathrm{b}}$ & $2,70 \pm 0,11^{\mathrm{c}}$ & $2,75 \pm 0,11^{\mathrm{c}}$ & $0,81 \pm 0,03^{\mathrm{d}}$ \\
\hline Hyperosidin asillenmis türevi & $\mathrm{C}_{21} \mathrm{H}_{20} \mathrm{O}_{12}$ & 505 & 463,301 & $0,45 \pm 0,02^{\mathrm{b}}$ & $0,52 \pm 0,03^{\mathrm{a}}$ & $0,27 \pm 0,01^{\mathrm{c}}$ & $0,16 \pm 0,01^{\mathrm{d}}$ & $0,08 \pm 0,00^{\mathrm{e}}$ \\
\hline Luteolin hexoside & & & & $0,69 \pm 0,04^{\mathrm{b}}$ & $0,83 \pm 0,04^{\mathrm{a}}$ & $0,42 \pm 0,02^{\mathrm{c}}$ & $0,27 \pm 0,01^{\mathrm{d}}$ & $0,13 \pm 0,01^{\mathrm{e}}$ \\
\hline Kuersetin-3-a-L-rhamno piranozit(Quercitrin) & $\mathrm{C}_{21} \mathrm{H}_{20} \mathrm{O}_{11}$ & 447 & 301 & $3,25 \pm 0,17^{\mathrm{b}}$ & $3,75 \pm 0,20^{\mathrm{a}}$ & $1,97 \pm 0,08^{\mathrm{c}}$ & $1,45 \pm 0,06^{\mathrm{d}}$ & $0,59 \pm 0,02^{\mathrm{e}}$ \\
\hline Kuersetin & $\mathrm{C}_{15} \mathrm{H}_{10} \mathrm{O}_{7}$ & 301 & 179,151 & $2,34 \pm 0,12^{\mathrm{b}}$ & $3,43 \pm 0,18^{\mathrm{a}}$ & $1,42 \pm 0,06^{\mathrm{c}}$ & $2,41 \pm 0,10^{\mathrm{b}}$ & $0,43 \pm 0,02^{\mathrm{d}}$ \\
\hline Rutin & $\mathrm{C}_{27} \mathrm{H}_{30} \mathrm{O}_{16}$ & 609 & 301 & $15,06 \pm 0,79^{a}$ & $0,36 \pm 0,02^{\mathrm{e}}$ & $9,13 \pm 0,38^{\mathrm{c}}$ & $10,24 \pm 0,43^{\mathrm{b}}$ & $2,74 \pm 0,11^{\mathrm{d}}$ \\
\hline I3II8-Biapigenin & & & & $3,35 \pm 0,18^{\mathrm{a}}$ & $2,61 \pm 0,14^{b}$ & $2,30 \pm 0,10^{c}$ & $2,79 \pm 0,12^{\mathrm{b}}$ & $0,62 \pm 0,03^{\mathrm{d}}$ \\
\hline Toplam FLV & & & & $51,12 \pm 2,69^{\mathrm{a}}$ & $39,76 \pm 2,09^{\mathrm{b}}$ & $33,85 \pm 1,42^{\mathrm{c}}$ & $40,78 \pm 1,7^{b}$ & $9,82 \pm 0,41^{\mathrm{d}}$ \\
\hline Genel Toplam & & & & $85,55 \pm 4,36^{\mathrm{a}}$ & $78,27 \pm 3,96^{b}$ & $37,63 \pm 1,57^{\mathrm{d}}$ & $45,66 \pm 1,90^{\mathrm{c}}$ & $38,41 \pm 1,60^{\mathrm{d}}$ \\
\hline
\end{tabular}

${ }^{\mathrm{a}-\mathrm{e}} \mathrm{Ayn}$ satırdaki farklı üstel harfler örnekler arasında önemli bir fark olduğunu göstermektedir ( $\left.\mathrm{p}<0.05\right)$. HP: Hypericum perfaratum $\mathrm{L}$. 


\section{Sarı Kantaron (Hypericum perforatum L.) Fenoliklerinin Karakterizasyonu, Antioksidan ve Antimikrobiyal Potansiyelinin Belirlenmesi}

\section{Sarı Kantaron Bitkisinin Antioksidan Kapasitesi}

Sarı kantaron bitkisinden elde edilen ektraktlardaki antioksidan kapasite potansiyeli DPPH ve ABTS yöntemleriyle saptanmıştır. Elde edilen veriler Tablo 2'de verilmiştir. Sarı kantaron bitkisindeki antioksidan kapasitenin DPPH yöntemiyle yapılan analiz sonuçlarının 16.81-40.77 $\mu \mathrm{m}$ Trolox/g arasında değiştiği saptanmıştır. Farklı çözücüler kullanılarak ekstraktların hazırlanması antioksidan kapasite potansiyelini istatistiksel yönden önemli $(\mathrm{p}<0.05)$ düzeyde farklılığa yol açmıştır. DPPH fenolik bileşiklerin radikal süpürücü faaliyetlerinin araştırılması için yararlı reaktiftir (Lebeau ve ark., 2000). ABTS yöntemindeki elde edilen antioksidan kapasite sonuçları ise 22.46-53.61 $\mu \mathrm{m} \quad$ Trolox $/ \mathrm{g}$ aralığında saptanmıştır.

Tablo 2. Sarı kantaron bitkisinin antioksidan kapasite analiz sonuçları ( $\mu \mathrm{m}$ Trolox $/ \mathrm{g}$ )

\begin{tabular}{|l|c|c|c|c|c|}
\hline & $\begin{array}{c}\text { HP-MetOH } \\
\text { Ekstraktı }\end{array}$ & $\begin{array}{c}\text { HP-EtOH } \\
\text { Ekstraktı }\end{array}$ & $\begin{array}{c}\text { HP-AY } \\
\text { Ekstraktı }\end{array}$ & $\begin{array}{c}\text { HP-ZY } \\
\text { Ekstaktı }\end{array}$ & $\begin{array}{c}\text { HP-Su } \\
\text { Ekstaktı }\end{array}$ \\
\hline DPPH & $40,77 \pm 2,18^{\mathrm{a}}$ & $37,13 \pm 1,98^{\mathrm{b}}$ & $16,81 \pm 0,78^{\mathrm{e}}$ & $20,83 \pm 0,95^{\mathrm{d}}$ & $24,21 \pm 0,80^{\mathrm{c}}$ \\
\hline ABTS & $53,61 \pm 2,84^{\mathrm{a}}$ & $48,87 \pm 2,58^{\mathrm{b}}$ & $22,46 \pm 1,02^{\mathrm{e}}$ & $27,68 \pm 1,24^{\mathrm{d}}$ & $30,97 \pm 1,04^{\mathrm{c}}$ \\
\hline
\end{tabular}

${ }^{a-e}$ Aynı satırdaki farklı üstel harfler örnekler arasında önemli bir fark olduğunu göstermektedir ( $\mathrm{p}<0.05)$. HP: Hypericum perfaratum L.

Tablo 2.'de görüldüğü gibi antioksidan potansiyeli en yüksek metanol ekstraktlarında ve en düşük ayçiçek yağı ekstraktlarında saptanmıştır. Altun ve ark. (2013) metanol ile elde edilen ekstraktların en yüksek antioksidan potansiyeli gösterdiğini bildirmișlerdir. Bir başka çalışmada Kalogeropoulos ve ark. (2010) Kuzey Yunanistan'da Hypericum perforatum bitkisinin metanolik ekstraktlarının DPPH yöntemi ile antioksidan kapasitelerini araştırdıkları çalışmada potansiyeli 890,2 mg Trolox/g olarak saptamışlardır. Diğer bir çalışmada Hypericum perfaratum L.'nin Surbistan'da yetişen yedi hypericum türünün etanol ekstraktlarında antioksidan potansiyellerini FRAP $(3,7 \mu \mathrm{mol} \quad \mathrm{Fe} 2+/ \mathrm{mg})$, DPPH $(20.5$ EC50 $\mu \mathrm{g} / \mathrm{mL})$ ve ABTS $(1.02$ mmolTrolox/g) yöntemleriyle saptamışlardır (Zdunic ve ark., 2017). Söz konusu çalıșmada sarı kantaron bitkisin etanol ekstraktlarında DPPH ve ABTS yöntemleriyle elde edilen antioksidan aktivite analiz sonuçları çalışmamızda elde edilen verilerle benzerlik göstermektedir. In vivo ve in vitro olarak yapılan çalışmalardan elde edilen sonuçlar sarı kantaronun etanol ekstraktının antioksidan aktivitesinin bitkinin yapisında bulunan rutin, hiperosid, quercitrin ve quercetinin bileșikleri ile korelasyonlu değiștiğini saptamışlardır (Zou ve ark., 2004). Çeşitli çalışmalarda sarı kantaronun yüksek antioksidan aktivitesinin yapısındaki fenolik bileșiklerden kaynaklandığı bildirilmiștir (Sagratini ve ark., 2008, Conforti ve ark., 2005, Radulovic ve ark., 2007).

\section{Sarı Kantaron Bitkisinin Antimikrobiyal Aktivite Potansiyeli}

Sarı kantaron bitkisinin metanol, etanol, ayçiçek yağı, zeytinyağı ve su ile hazırlanan ekstraktlarının antimikrobiyal aktiviteleri agar kuyu difüzyon yöntemi kullanılarak belirlenmiştir. Antimikrobiyal aktivite analizlerinde Staphylococcus aureus ATCC 29213, Escherichia coli ATCC 25922 ve Pseudomonas aeuroginasa ATCC 27853 bakterileri test mikroorganizmaları olarak kullanılmıştır. İnkübasyon sonunda Hypericum perfaratum L. ekstraktlarında saptanan antimikrobiyal aktivite analiz sonuçları Tablo 3'de verilmiştir. 


\section{Sarı Kantaron (Hypericum perforatum L.) Fenoliklerinin Karakterizasyonu, Antioksidan ve Antimikrobiyal Potansiyelinin Belirlenmesi}

Tablo 3. Sarı kantaron bitkisinin antimikrobiyal aktivite analiz sonuçları

\begin{tabular}{lccc}
\hline \multirow{2}{*}{ Ekstraktlar } & \multicolumn{3}{c}{ Zon Çapı (mm) } \\
\cline { 2 - 4 } & Escherichia coli** & $\begin{array}{c}\text { Staphylococcus } \\
\text { aeureus* }\end{array}$ & $\begin{array}{c}\text { Pseudomonas } \\
\text { aeuroginasa** }\end{array}$ \\
\hline HP-MetOH Ekstraktı & $13.85 \pm 0.11$ & $13.52 \pm 0.44$ & $13.20 \pm 0.54$ \\
HP-EtOH Ekstraktı & $12.50 \pm 0.39$ & $14.08 \pm 0.37$ & $14.97 \pm 0.44$ \\
HP-Su Ekstraktı & $10.23 \pm 0.59$ & $9.76 \pm 0.26$ & $9.22 \pm 0.46$ \\
HP-AY Ekstraktı & - & - & - \\
HP-ZY Ekstaktı & - & - & -
\end{tabular}

(-): Zon oluşumu gözlemlenmedi, *gram (+) pozitif bakteriler, **gram (-) negatif bakteriler. HP: Hypericum Perfaratum L.

Antimikrobiyal aktivite analiz sonuçları incelendiğinde sarı kantaron bitkisinin ayçicek yağı ve zeytinyağı ile hazırlanan ekstraktlarının Escherichia coli, Staphylococcus aeureus, Pseudomonas aeuroginasa mikroorganizmaları üzerinde inhibisyon etkisi gözlemlenmezken, metanol, etanol ve su ile hazırlanan ekstraktları antimikrobiyal etki saptanmıştır. Test edilen mikroorganizmalara karşı en düşük antimikrobiyal aktivite su ile hazırlanan bitki ekstraktında gözlemlenmiştir. Mazandarani ve ark. (2007) $H$. perforatum ve $H$. androsaemum türlerinin antibakteriyel aktivitesini araştırdıkları çalışmada sulu ekstraktlarda tüm test mikroorganizmalarına karşı zayıf antibakteriyel etki gözlemlediklerini bildirmişlerdir. Hypericum Perforatum L.' nin antibakteriyel aktivitesinin araştırıldığ bir çalışmada Saddiqe ve ark. (2010), kantaron bitkisinin Gram (+) bakterilere karşı Gram (-) bakterilere kiyasla daha yüksek bir antibakteriyel aktiviteye sahip olduğunu ve alkollü ekstraktların (metanolik/etanolik) sulu ekstraktlardan daha güçlü aktivite gösterdiğini ifade etmişlerdir. Brezilya'nın güneyinde yetişen altı Hypericum türünün metanolik özütlerinin antimikrobiyal aktivitesinin araştırıldığ bir çalışmada en aktif antimikrobiyal etkinin Staphylococcus aeureus üzerinde gözlemlendiği bildirilmiştir (Agnol ve ark., 2003). Conforti ve ark. (2005) İtalya'da yetişen metanol ektraktının antibakteriyel aktivitesini araştırdıkları bir çalışmada Hypericum perfaratum L'un ilk sırada Staphylococcus aeureus yer almak üzere Gram pozitif bakterilere karş1 antibakteriyel aktivite gözlemlediklerini bildirmişlerdir.

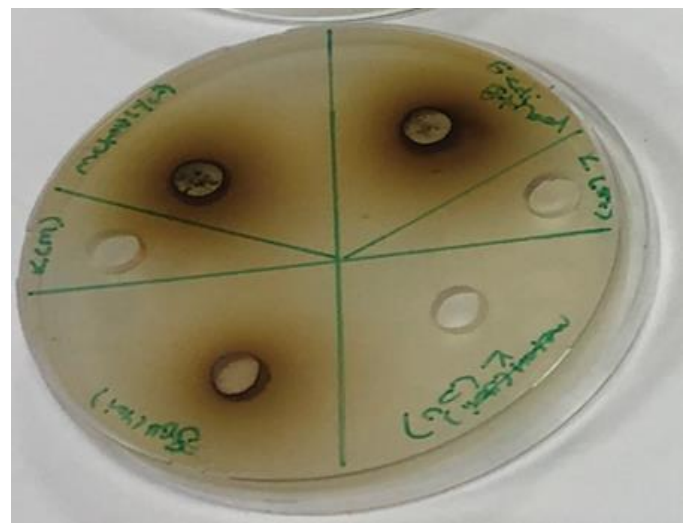

Şekil 7. Sarı kantaron bitkisinin ekstraktlarının Escherichia coli mikroorganizmasına karşı oluşturduğu zon çapları görüntüleri.

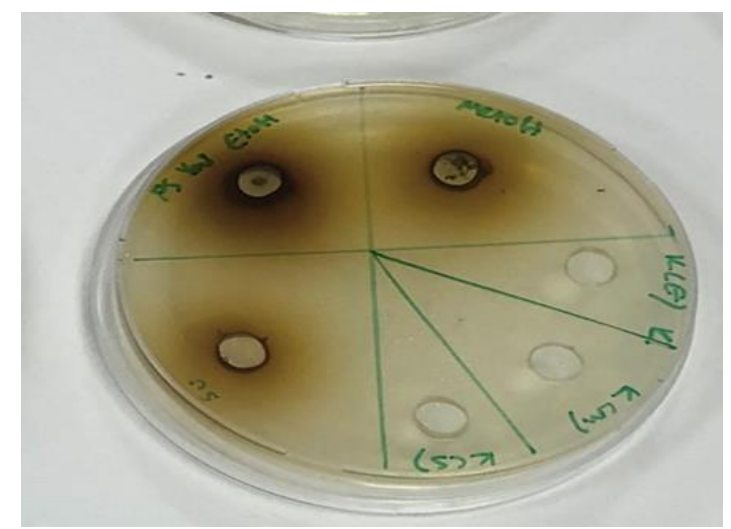

Şekil 8. Sarı kantaron bitkisinin ekstraktlarının Pseudomanas aeruginosa mikroorganizma- sina karşı oluşturduğu zon çapları görüntüleri 


\section{Sarı Kantaron (Hypericum perforatum L.) Fenoliklerinin Karakterizasyonu, Antioksidan ve Antimikrobiyal Potansiyelinin Belirlenmesi}

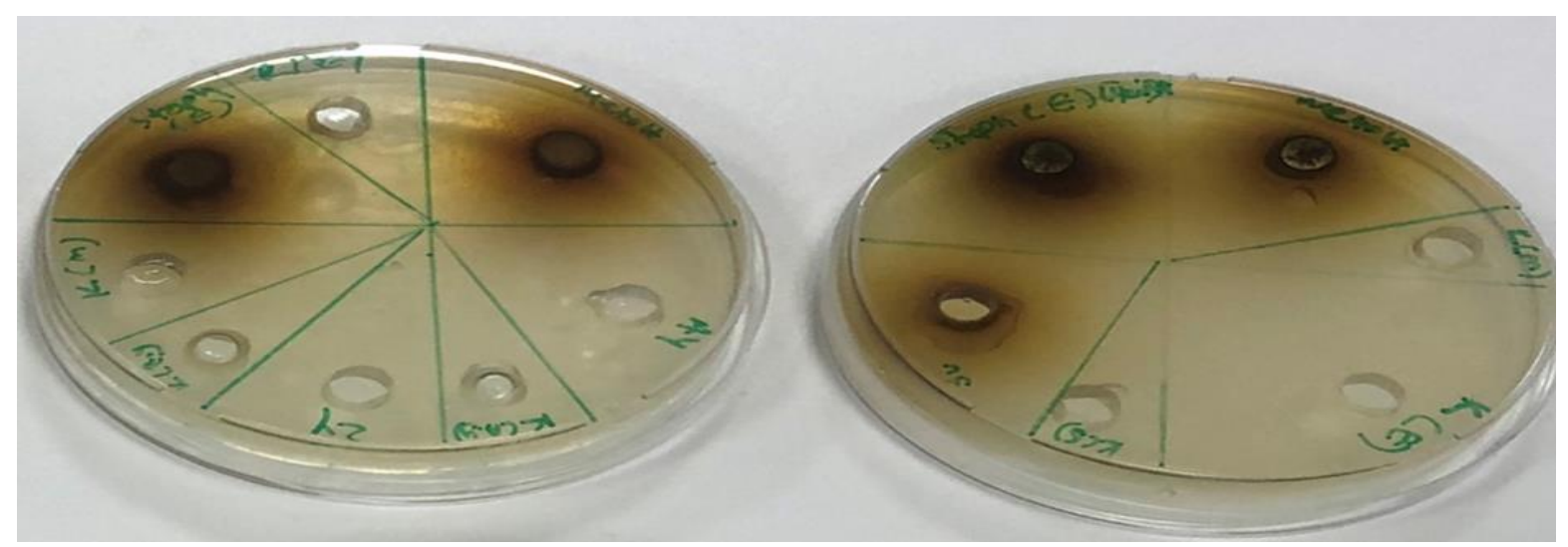

Şekil 9. Sarı Kantaron bitkisinin ektraktlarının Staphylacoccus aereus aureus mikroorganizmasına karşı oluşturduğu zon çapları görüntüleri

Tüm sonuçlar genel olarak değerlendirildiğinde; etanol ve metanol ile hazırlanan ekstraktlarda tanımlanan fenolik bileşik sayısının ve miktarının daha fazla olduğu, antioksidan potansiyelin diğer ekstraktlara oranla daha yüksek saptandığı, test mikroorganizmaları üzerinde önemli inhibisyon etkisinin gözlendiği sonucuna varılmıştır. Fenolik maddelerin ekstraksiyonunda metanol ve etanolün en iyi sonuçları verdiği, naftodiantronların elde edilmesi amaciyla yağ ve yağ bazlı ekstraksiyonların yapılmasi gerektiği sonucuna varılmıştır. Gıdalarda oksidasyonu önlemede alternatif olarak önemli yer tutan fenolik bileşiklerin sarı kantaron bitkisinde bol miktarda bulunması bu bitkinin gida üretimlerinde koruyucu olarak kullanılabilmesinde önemli bir potansiyeli bulunmaktadır. Ülkemizde doğal olarak yetişen sarı kantaron bitkisinin yapısındaki yararlı bileşikler açısından gıda ve tıbbi ve aromatik bitkiler sektöründe hak ettiği yeri alabilmesi için üzerinde yapılan çalışmaların yoğunlaştırılması gerektiği ve biyoaktif bileşiklerin verimli bir şekilde orta çıarılmasının önemli olduğu düşünülmektedir.

\section{Kaynaklar}

Agnol, R.D., Ferraz, A., Bernardi, A. P., Albring, D., Nör, Sarmento, C., L., Lamb, L., Hass, M., Poser, G. ve Schapoval, E. S. (2003). Antimicrobial activity of some Hypericum species. Phytomedicine, 10, 511-516.
Almeida, J. S., Benvegnú, D. M., Boufleur, N., Reckziegel, P., Barcelos, R. C. S., Coradini, K., ... Beck, R. C. R. (2011). Hydrogels containing rutin intended for cutaneous administration: efficacy in wound healing in rats. Drug Development and Industrial Pharmacy, 38(7), 792-799.

Altan, A., Damlar,İ., Aras, M.H. ve Alpaslan, C. (2015). Effect of St. John's Wort (Hypericum perforatum) on wound healing. Archives Medical Review Journal, 24(4), 578-591.

Altun, M. L., Sever Y.B., Orhan, İ.E. ve Çitoglu, G.S. (2013). Assessment of cholinesterase and tyrosinase inhibitory and antioxidant effects of Hypericum perforatum L. (St. John's wort). Industrial Crops and Products, 43, 8792.

Atalay, D. ve Erge, H.S. (2018). Gida takviyeleri ve sağlik üzerine etkileri. Food and Health, 4(2), 98-111.

Aydın, S., Ilgaz, C., Kadiroğlu, P. (2021) Prediction of Quality Properties of Carob Fruit with FT-IR Spectroscopy. Journal of Raw Materials to Processed Foods, 2, 24-32. 


\section{Sarı Kantaron (Hypericum perforatum L.) Fenoliklerinin Karakterizasyonu, Antioksidan ve Antimikrobiyal Potansiyelinin Belirlenmesi}

Baytop, T. (1999). Türkiye'de Bitkilerle Tedavi, Nobel T1p Yayınevi. 2. Baskı. İstanbul, s. 256.

Becker, L., Zaiter, A., Petit, J., Zimmer, D., Karam, M.C., Baudelaire, E., Scher, J. ve Dicko, A. (2016). Improvement of antioxidant activity and polyphenol content of Hypericum perforatum and Achillea millefolium powders using successive grinding and sieving. Industrial Crops and Products, 87, 116123.

Brand-Williams, W., Cuvelier, M.E. ve Berset, C. (1995). Antioxidative activity of phenolic composition of commercial extracts of sage and rosemary. LWT Food Science and Technology, 28, 2530.

Chen, W.C., Liou, S.S., Tzeng, T.F., Lee, S.L. ve Liu, I.M. (2013). Effect of topical application of chlorogenic acid on excision wound healing in rats. Planta Medica, 79(08), 616-621.

Chimshirova, R., Karsheva, M., Diankov, S. ve Hinkov, I. (2019). extraction of valuable compounds from Bulgarian St. John's Wort (Hypericum perforatum L.). antioxidant capacity and total polyphenolic Content. Journal of Chemical Technology and Metallurgy, 54, 5, 952-961.

Conforti, F., Statti, G. A., Tundis, B., Bianchi, A., Agrimonti, C., Sacchetti, G., Andreotti, E., Menichini, F. ve Poli, F. (2005). Comparative chemical composition and variability of biological activity of methanolic extracts from Hypericum perforatum $\mathrm{L}$. Natural Product Research, 19(3), 295,303.

Çırak, C., ve Kurt, D., (2014). Önemli Tıbbi Bitkiler Olarak Hypericum Türleri ve Kullanım Alanları, Anadolu, J. of AARI $24,38-52$.
Ernst, E., (2003) ed. Hypericum:The Genus Hypericum. CRC Press.

Gopalakrishnan, A., Ram, M., Kumawat, S., Tvean, S. ve Kumar, D. (2016). Quercetin accelerated cutaneous wound healing in rats by increasing levels of VEGF and TGF- $\beta 1$. Indian Journal of Experimental Biology, 54, 187-195.

Güner A, Özhatay N, Ekim T, ve Baser KHC., (2000). Flora of Turkey and the East Aegean Islands. Royal Botanic Garden Edinburgh, Edinburgh University Press, 92-94.

Güner, A., Aslan, S., Ekim, T., Vural, M., ve Babaç., M. T., (2012). Türkiye Bitkileri Listesi (Damarlı Bitkiler), Nezahat Gökyiğit Botanik Bahçesi ve Flora Araştırmaları Derneği Yayını.

Hosni, K., Msaâda, K., Taârit, M. B., Hammami, M., ve Marzouk, B. (2010). Bioactive components of three Hypericum species from Tunisia: A comparative study. Industrial Crops and Products, 31(1), 158-163.

Jürgenliemk, G. ve Nahrstedt, A. (2002). Phenolic compounds from Hypericum perforatum, Planta Medica, 68(01), 8891.

Kalogeropoulos, N., Yannakopoulou, K., Gioxari, A., Chiou, A., ve Makris, D. P. (2010). Polyphenol characterization and encapsulation in $\beta$-cyclodextrin of a flavonoid-rich Hypericum perforatum (St John's wort) extract. LWT- Food Science and Technology, 43(6), 882889.

Kang, J.W. ve Lee, S.M. (2014). Protective effects of chlorogenic acid against experimental reflux esophagitis in rats. Biomolecules and Therapeutics, 22(5), 420-425. 


\section{Sarı Kantaron (Hypericum perforatum L.) Fenoliklerinin Karakterizasyonu, Antioksidan ve Antimikrobiyal Potansiyelinin Belirlenmesi}

Kasper, S., ve Dienel, A. (2002). Cluster analysis of symptoms during antidepressant treatment with Hypericum extract in mildly to moderately depressed outpatients. A meta-analysis of data from three randomized, placebo-controlled trials. Psychopharmacology 164, 301308.

Kelebek, H., Sevindik, O., Uzlasir, T., Selli, S. (2020). LC-DAD/ESI MS/MS characterization of fresh and cooked Capia and Aleppo red peppers (Capsicum annuum L.) phenolic profiles. European Food Research and Technology, 246(10), 1971-1980.

Kelebek, H., Selli, S., Canbaş, A. ve Cabaroglu, T. (2009). HPLC Determination of organic acids, sugars, phenolic compositions and antioxidant capacity of orange juice and orange wine made from a Turkish Cv. Kozan. Microchemical Journal, 91, 187-192.

Lebeau, J., Furman, C., Bernier, J.-L., Duriez, P., Teissier, E., ve Cotelle, N. (2000). Antioxidant properties of di-tert butylhydroxylated flavonoids. Free Radical Biology and Medicine, 29(9), 900-912.

Lecrubier, Y., Clerc, G., Didi, R., ve Kieser, M. (2002). Efficacy of St. John's Wort Extract WS 5570 in major depression: A Double-Blind, Placebo-Controlled Trial. American Journal of Psychiatry, 159(8), 1361-1366.

Mazandarani, M., Yassaghi, S., Rezaei, M.B., Mansourian, A.R. ve Ghaemi, E.O. (2007). Ethnobotany and antibacterial activities of two endemic species of Hypericum in North-East of Iran. Asian Journal of Plant Sciences, 6, 354-358.

Marrelli, M., Conforti, F., Toniolo, C., Nicoletti, M., Statti, G. ve Menichini, F. (2014). Hypericum perforatum: Habitatın kimyasal bileșim, foto- kaynakl1 sitotoksisite ve antiradikal aktivite üzerindeki etkileri. Farmasötik Biyoloji, 52 (7), 909-918.

Orhan, E. I. ve Kartal, M. (2015). LC-DAD-MSassisted quantification of marker compounds in Hypericum perforatum L. (St. John's Wort) and its antioxidant activity. Turk J Pharm Sci 12(3), 279286.

Öztürk, I., Çalişkan, O., Tornuk, F., Ozcan, N., Yalcin, H., Baslar, M., ve Sagdic, O. (2015). Antioxidant, antimicrobial, mineral, volatile, physicochemical and microbiological characteristics of traditional home-made Turkish vinegars. LWT- Food Science and Technology, 63, 144-151.

Parzhanova, A.B. Petkova, N.Tr., Ivanov, I. G. ve Ivanova, S. D., (2018). Evaluation of biologically active substanceand antioxidant potential of medicinal plants extracts for food and cosmetic purposes. Journal of Pharmaceutical Sciences and Research, 10(7), 1804-1809.

Radulovic, N., Stankov-Jovanovic, V., Stojanovic, G. Melcerovic, A. S., Spiteller, M. ve Asakawa,Y. (2007). Screening of in vitro antimicrobial and antioxidant activity of nine Hypericum species from the Balkans. Food Chemistry 103, 15-21.

Raziq, N., Muhammad, N., Chishti, K.A., Saeed, M., Rahman, S. ve Khan, H. (2011). Correlation of the antioxidant capacity with thephenolic contents of Hypericum monogynum and Hypericum perforatum. African Journal of Pharmacy and Pharmacology, 5(16), 1872-1876.

Saafi, E.B., Arem, A.E., Issaoui, M., Hammami, M. ve Achour, L. (2009). Phenolic content and antioxidant activity of four date palm (Phoenix dactylifera L.) fruit varieties grown in Tunisia. International 


\section{Sarı Kantaron (Hypericum perforatum L.) Fenoliklerinin Karakterizasyonu, Antioksidan ve Antimikrobiyal Potansiyelinin Belirlenmesi}

Journal of Food Science and Technology, 44, 2314-2319.

Saddiqe, Z, Naeem I, ve Maimoona A. (2010). A review of the antibacterial activity of Hypericum perforatum L. Journal of Ethnopharmacology, 131, 511-21.

Sagratini, G., Ricciutelli, M., Vittori, S., Ozturk, N., Ozturk, Y. ve Maggi, F. (2008). Phytochemical and antioxidant analysis of eight Hypericum taxa from Central Italy. Fitoterapia, 79, 210-213.

Sánchez-Muniz, F.J., Olivero-David, R., Triki, M., Salcedo, L., González-Muñoz, M. J., Cofrades, S., Ruiz-Capillas, C., Jiménez-Colmenero $\mathrm{F}$. ve Benedi, J. (2012). Antioxidant activity of Hypericum perforatum L. extract in enriched n-3 PUFA pork meat systems during chilled storage. Food Research International, 8,2, 909-915.

Sarıürkçü C., Locatelli, M., Tartaglia, A., Ferrone, V., Juszczak, A. M., Özer, M. S., Tepe B. ve Tomczyk, M. (2020). Enzyme and biological activities of the water extracts from the plants Aesculushippocastanum, Oleaeuropaea and Hypericum perforatum that are used as folk remedies in Turkey. Molecules, 25(5), 1202.

Sasmaz, H. K., Uzlasir, T., Kelebek, H. (2020). Effect of infusion time on the phenolic profile and some physicochemical properties of Lavandula $\mathrm{x}$ intermedia cv.'SUPER'. Journal of Raw Materials to Processed Foods, 1, 55-71.

Seyrekoğlu, F. ve Temiz, H. (2020). Effect of extraction conditions on the phenolic content and DPPH radical scavenging activity of Hypericum perforatum L. Turkish Journal of Agriculture - Food Science and Technology, 8(1), 226-229.
Silva, A. B., Ferreres, F., Malva, J. O. ve Dias, A. C. P. (2005). Phytochemical and antioxidant characterization of $\mathrm{H}$. Perforatum alcoholic extracts. Food Chemistry, 90, 157-167.

Silva, B. A., Malva, J. O., ve Dias, A. C. P. (2008). St. John's Wort (Hypericum perforatum) extracts and isolated phenolic compounds are effective antioxidants in several in vitro models of oxidative stress. Food Chemistry, 110(3), 611-619.

Skerget, M., Kotnik, P., Hadolin, M., Hras, A. R., Simonic, M., ve Knez, Z. (2005). Phenols, proanthocyanidins, flavonesand flavonols in some plant materials and their antioxidant activities. Food Chemistry, 89(2), 191-198.

Solomon, D., J. Adams,ve N. Graves. (2013). Economic evaluation of St. John's wort (Hypericum perforatum) for the treatment of mild to moderate depression. Journal of Affective Disorders 148, 228-234.

Wölfle, U., Seelinger, G. ve Schempp, C. M. (2014). Topical Application of St. John's Wort (Hypericum perforatum). Planta Medica, 80, 109-120.

Zdunic, G., Godjevac, D., Savikin, K. ve Petrovic S. (2017). Comparative Analysis of Phenolic Compounds in Seven Hypericum Species and Their Antioxidant Properties. Natural Product Communications, 12,11,1805-1811.

Zou, Y., Lu, Y., ve Wei, D. (2004). Antioxidant Activity of a Flavonoid-Rich Extract of Hypericum perforatum L.in Vitro. Journal of Agricultural and Food Chemistry, 52(16), 5032-5039. 